\title{
Shared Mind: Communication, Decision Making, and Autonomy in Serious Illness
}

\author{
Ronald M. Epstein, MD \\ Richard L. Street, Jr, PbD ${ }^{2}$
}

'Departments of Family Medicine, Psychiatry, and Oncology, School of Medicine \& Dentistry, and the and School of Nursing, University of Rochester Medical Center, Rochester, New York

${ }^{2}$ Department of Communication, Texas A\&M University; and Houston Center for Quality of Care and Utilization Studies, Baylor College of Medicine, Houston, Texas

\begin{abstract}
In the context of serious illness, individuals usually rely on others to help them think and feel their way through difficult decisions. To help us to understand why, when, and how individuals involve trusted others in sharing information, deliberation, and decision making, we offer the concept of shared mindways in which new ideas and perspectives can emerge through the sharing of thoughts, feelings, perceptions, meanings, and intentions among 2 or more people. We consider how shared mind manifests in relationships and organizations in general, building on studies of collaborative cognition, attunement, and sensemaking. Then, we explore how shared mind might be promoted through communication, when appropriate, and the implications of shared mind for decision making and patient autonomy. Next, we consider a continuum of patient-centered approaches to patient-clinician interactions. At one end of the continuum, an interactional approach promotes knowing the patient as a person, tailoring information, constructing preferences, achieving consensus, and promoting relational autonomy. At the other end, a transactional approach focuses on knowledge about the patient, information-as-commodity, negotiation, consent, and individual autonomy. Finally, we propose that autonomy and decision making should consider not only the individual perspectives of patients, their families, and members of the health care team, but also the perspectives that emerge from the interactions among them. By drawing attention to shared mind, clinicians can observe in what ways they can promote it through bidirectional sharing of information and engaging in shared deliberation.
\end{abstract}

Ann Fam Med 2011;9:454-461. doi:10.1370/afm.1301.

\section{INTRODUCTION}

I

$\mathrm{n}$ the context of serious illness, individuals usually rely on others to help them think and feel their way through difficult decisions. Yet, we

know very little about why, when, and how individuals involve trusted others in their care. Recognizing that information, deliberation, and decisions often occur within relationships, health professionals and social scientists have called for richer conceptualizations of autonomy and decisionmaking processes. ${ }^{1-14}$

In this article, we explore how relationships can inform decision-making in clinical practice, considering how information, emotions, values, and autonomy are shared among patients, family members, and health professionals. Providing high-quality information about disease-related factors has been the focus of many efforts to improve decision making, yet we know little about how information is used by patients and their families. Shared decision making has often been conceptualized as a process of matching of choices to patients' values and preferences with the goal of promoting individual autonomy, however, people often rely on others to define and weigh the values that shape their decisions. ${ }^{5}$ These influences can be both positive (eg, clarifying a discussion) or negative (eg, mindlessly adopting another's perspective as one's own). Emotions can strongly shape preferences ${ }^{15}$; even so, although patients report strong emotional 
bonds to their physicians, most emotions in patientphysician interactions are unspoken. ${ }^{16}$ There has been progress in helping patients to be more active in decisions, but patients, physicians, and communication experts have different criteria for shared decisions. ${ }^{17}$

In this article, we propose an interactional approach as one anchor for a continuum of decision-making processes in which relational autonomy emerges through shared information, shared deliberation, and shared mind. By shared mind, we mean situations in which new ideas and perspectives emerge through the sharing of thoughts, feelings, perceptions, meanings, and intentions among 2 or more people. ${ }^{18}$ Shared mind can be conceptualized as an achievement (eg, consensus), but we are more interested in shared mind as an interpersonal process (eg, becoming attuned) that is present to varying degrees in human interactions.

The concept of shared mind coalesces some of the recent thinking about decision making and derives from 2 observations: (1) that much of what we consider personal or individual (eg, our preferences, values, and attitudes) is socially mediated ${ }^{18,19}$; and (2) that humans communicate and understand each others' subjective experiences through multiple pathways_-spoken language, expressed emotion, meaningful actions. In our view, shared mind in decision making is both discovered (as a naturally occurring phenomenon) and created (resulting from effort on the part of clinician or patient). With awareness, clinicians and patients can learn how to recognize shared mind when it is occurring naturally, recognize when it is not, and, when appropriate, change their behavior to promote it. To illustrate, we will first consider a clinical situation, then describe attributes and processes underlying shared mind.

Richard Grayson (a pseudonym, based on an actual patient) was a retired and intellectually active professor of epidemiology with recently diagnosed cancer of the pancreas. After consulting 2 oncologists and a surgeon, he was offered conflicting recommendations and a limited range of options. Surgery was unlikely to improve survival or quality of life. Although initially he thought he would never consider chemotherapy for an incurable cancer, Mr Grayson was surprised that chemotherapy offered a $30 \%$ chance of life extension by 2 to 3 months, and might improve his quality of life-but with the risk of side effects. Still, no one could know whether he would be one of the lucky $30 \%$ whose cancer would respond or whether palliation alone might offer more comfort. In addition to local options (choice between 2 chemotherapy regimens and a phase 3 clinical trial comparing high- and low-intensity regimens), he also considered phase 1 trials of promising new drugs and alternative regimens currently favored in Europe. Yet, as an epidemiolo- gist, he was exquisitely aware that he was both older and had more extensive tumor burden than the clinical trial study populations, limiting their applicability to his own condition. He also knew that his logical analysis of the situation was hijacked by strong affect; he was often overwhelmed rather than enlightened by more information.

Despite being well-informed and having good social support, excellent access to medical care, and a trusting patient-physician relationship, he felt lost. Mr Grayson, accompanied by his partner, asked his family physician, "What would you do if you were me?" His physician responded, "I might have different values and preferences than you do, so, let's focus on what's most important to you." This commonly advocated approach assumes that Mr Grayson has a set of personal values that would guide him through this particular situation, and that his preferences would be clear if his physician only asked. It assumes that his values are static, and exist in him as an individual, rather than as a dynamic dialogue that also engages his close social networks. Although Mr Grayson had written advance directives and could articulate broad values and preferences-his desire to live, avoid suffering and avoid iatrogenic harm-he had difficulty translating general principles into a concrete choice in this specific context. Furthermore, contemplating the choice only accentuated $\mathrm{Mr}$ Grayson's sense of burden.

Dr Porter, his family physician, also found it difficult to provide clear answers. The effectiveness data were ambiguous. Chemotherapy might make things better or might make things worse. Traveling to other centers would be tiring and reduce contact with social supports. Dr Porter wondered whether she should help the patient make a decision, make a stronger recommendation, or engage others in the discussion to spare the patient the burden of deciding. ${ }^{20}$ In trying to honor Mr Grayson's individual autonomy (eg, clarify his preferences, make wise decisions), she also recognized his limited ability to do so without the input from trusted others.

In seeking others to help him understand his values and feelings, cope with uncertainty, sort out his options, and navigate his way, Mr Grayson changed from being uninformed but certain (that chemotherapy would not be useful in this circumstance) to being informed and uncertain (it might be); his preferences also changed from being stable (no chemotherapy) to being unstable (not knowing what to think). After some time, a set of values, preferences, and plans emerged that not been previously voiced by any of the individuals - in this case, a time-limited clinical trial of second-line chemotherapy with the option for dose reduction, concurrent palliative care, and changing 
from full-code to do-not-attempt-resuscitation status. Mr Grayson, his family, and his physicians believed that the decision was mutually endorsed, clinically reasonable, emotionally calming, and somehow made sense in the context of the mutually constructed set of goals and values. This decision - in the face of a complex and overwhelming situation-was not made by an individual. Rather, the decision was built ${ }^{21}$ within partnerships that enabled Mr Grayson to participate meaningfully in care.

\section{ARE TWO MINDS BETTER THAN ONE?}

Observations about Mr Grayson and other patients have led us to consider an interactional view of care. Clinicians, family members, and relevant others did not merely help Mr Grayson clarify his own preferences so he could make an individual autonomous decision. Rather, they interacted in such a way that all parties considered new information, perspectives and options - the decision emerged out of collective thinking and feeling. Put another way, a 2-way conversation considers 3 minds - the patient's, the clinician's, and that which is shared between them. We take this view for several reasons.

First, in general, important health decisions are usually not made in isolation. They are usually made in the context of social networks with friends, family, other social contacts, and health care professionals. ${ }^{12}$ These social networks emerge and change when patients develop serious or chronic illnesses. Whereas a healthy person might have a sustained relationship with one primary care physician or with a small number of health care professionals, those with serious and chronic illnesses have multiple connections to the health care system - they interact with many interrelated physicians, nurses, and therapists. Their family members, caregivers, and friends have additional health-related interactions with each other, the patient, and the clinicians involved in patients' care. ${ }^{22}$ Professional networks of clinicians can grow increasingly complex when caring for seriously ill patients. Yet, we know little about when and how decisions are made within these complex, emergent social networks.

Second, patients' preferences may be vague, unstable, and uninformed. Although some patients have underlying values and preferences that clearly apply to the health care decision at hand, often these values and preferences have not been previously examined, are general (eg, longevity and quality of life) rather than contextualized to the specific decision (eg, whether to choose disfiguring surgery with a low chance of cure), and are in conflict with other articulated values and preferences. ${ }^{23}$ In simple, familiar, and anticipated situations, preferences tend to be stable, predictable, and consistent. Preferences in complex, ambiguous, unfamiliar, and affectively charged situations, however, often are not ${ }^{24,25}$ i in such situations preferences tend to be remarkably sensitive to subtle effects of framing, ordering, tone of voice, word choice, and recent experiences. ${ }^{25}$ Rationales for each preference may sound quite logical, but they are often constructed as an afterthought. ${ }^{26}$ Furthermore, people often are not adept at predicting how they will feel after a future event has occurred (ie, affective forecasting) 27,28 and often underestimate their own ability to adapt to adversity. Thus, unassisted, patients' decisions might be neither truly informed nor autonomous, and patients may have limited insight into their own cognitive biases and limitations. Clinicians' preferences and decision-making processes are similarly affected.

Third, patients often make medical decisions to take care of someone else's psychological needs, sometimes compromising their own physical or emotional well-being. A patient may opt for chemotherapy in advanced cancer "because my family would be too upset if they thought I was giving up." Although the moral implications of such decisions are complex, the presence of others' needs points to fundamental flaws in the assumption that individuals consider a good decision solely in terms of their own health. Rather, exposing this kind of logic allows it to be examined and challenged, and patients can be offered other ways to address both their own needs and those of their family members.

Finally, an otherwise cognitively intact person with a serious illness often has difficulty processing complex information and ambiguity. Among seriously ill hospitalized adults who have no evidence of dementia, one study reported that cognitive testing was at a level similar to a 10-year-old-including concrete thinking and inability to attend to more than one idea at a time. ${ }^{29}$ Furthermore, in this diminished cognitive state, patients often have to deal with uncertainty, sort through massive amounts of decontextualized information, consider multiple options, and face the emotional impact of the illness. Faced with complex, ambiguous, and emotionally laden circumstances (cognitive overload), a person will tend to ignore data, simplify tasks, and make hasty decisions, that is, revert to rules of thumb and stereotypes rather than explore the full range of his or her values and the scientific data. ${ }^{30-32}$ Thus, seriously ill patients may need, and often seek, help from others to recall and process information. Clinicians also suffer from cognitive overload, increasing their propensity to rely on similar mental shortcuts and not question their own oversimplifications. ${ }^{33-41}$ 


\section{SHARED MIND}

Mr Grayson's situation shows how shared mind includes cognitive (eg, shared ideas, values, goals, or decisions), affective (feelings, emotions), and motor (eg, mirroring each others' facial expressions and gestures) elements. ${ }^{42-48}$ Here, we explore the literature on shared mind $^{18}$ and related areas-collaborative cognition, attunement, and sensemaking. Although these studies have been largely in nonmedical contexts, these ideas can be applied to clinicians' experiences with patients.

\section{Collaborative Cognition}

Like Mr Grayson, most seriously ill patients bring family members to consultations. ${ }^{22}$ In these high-stress high-stakes situations, individuals can bolster each others' thinking, ${ }^{49}$ compensating for deficits in each others' ability to process information and solve problems. This process, often described in those who have impaired (eg, older adults) or immature (eg, children) thinking, has been called collaborative cognition. Patients whose cognition is compromised by fatigue, information overload, and emotional distress thus ask family members to help with recall and sort through complex information and choices; collaboration might also reduce patients' anxiety and help them process information more effectively. Support groups and online communities can further act as collaborators, as can religious or spiritual communities that share common values. Clinicians themselves engage in collaborative cognition in the form of team rounds in teaching hospitals, where often the group arrives at better decisions than any single individual. Yet, family members' contributions to decision making are frequently ignored in clinical consultations and in research on decision making.

\section{Attunement}

Whereas collaborative cognition refers to problem solving, the concept of attunement refers to a feeling — of being on the same wavelength or in stride with another person. For Mr Grayson, a sense of feeling known formed the basis for mutual understanding, empathy, and compassion. ${ }^{50}$ In health care, evidence for attunement may be seen in the way patients participate in consultations, physicians respond to patients, and how they each adapt to each others' communicative styles. ${ }^{16}$ Attunement has been described in newborns, suggesting that these are basic biological mechanisms that promote attachment and learning of essential survival skills ${ }^{51}$; these mechanisms seem to be equally applicable in the verbal world of adult human relationships. ${ }^{51,52}$

In health care, attunement has been described within patient-clinician dyads, ${ }^{42,49,53,54}$ family and social systems, ${ }^{55}$ health care teams, ${ }^{56}$ teacher-learner relationships, ${ }^{57,58}$ organizations, ${ }^{59}$ and communities of care. ${ }^{60,61}$
Cognitive neuroscientists, ${ }_{1}^{18,62,63}$ using functional neuroimaging studies, are now proposing a neural basis of attunement, building upon prior observations by philosophers ${ }^{64-67}$ and psychotherapists. ${ }^{68,69}$ For example, research suggests that specialized neurons (mirror neurons) fire in response to viewing purposeful actions undertaken by others, allowing us to imitate and interpret their intentions by mapping their observed actions onto our own premotor cortex..$^{47,48,70}$ Some researchers suggest that there are also affective neural resonance systems that promote attunement to others' emotions. ${ }^{43,50,62,65,71,72}$ Attunement also may have an important role in decision making and empathy; a sense of connection with trust can emerge during a discussion, for which none of the participants take full credit, that in turn promotes a stronger belief in and commitment to a treatment decision. Attunement implies that the patient and family can be the focus of care as well as de facto members of the health care team.

\section{Sensemaking}

Attunement and collaborative cognition among members of a team or an organization can contribute to sensemaking, in which collective brainstorming and sharing experiences generate meaning, solve problems, and make decisions. ${ }^{73,74}$ Sensemaking can apply to enduring, highly structured teams (eg, a liver transplant team), as well as more loosely constructed communities of care (eg, a primary care physician's referral network). ${ }^{60,61,75,76}$ The products of sensemaking (eg, shared meaning) in turn can influence subsequent understanding and decisions. This iterative process can help participants appreciate new perspectives, meaningfully discuss values and preferences, and inhibit a common tendency of individuals and groups to oversimplify complex situations and processes. Thus, qualities of well-functioning teams would include attentiveness, vigilance, nonjudgmental attitudes, and tolerance of complexity — qualities associated with mindfulness and reflection. ${ }^{75-77}$

\section{COMMUNICATION THAT PROMOTES SHARED MIND}

Relationships and organizations are networks of conversations. Mr Grayson, his family, and his clinical team had conversations that were characterized by cooperative efforts to create coherence and meaning. ${ }^{78}$ Clinicians listened attentively, expressed curiosity and interest, explored emotions, and responded to his requests for help, ${ }^{79-82}$ which, in turn, promoted not only sharing of information but also shared deliberation. ${ }^{80}$ Shared mind might happen during a single conversation, or it might be the result of a history of interactions among patients, family, and clinicians. Shared 
mind may be facilitated by personality factors, such as openness; relational factors, such as respect and trust; and organizational factors that promote and value time spent with patients.

\section{Shared Information}

Shared information should be the right quantity (neither insufficient nor overload), ${ }^{83}$ relevant to the patient's situation, and meaningful to the patient. Relevant information might include objective information about the disease, treatment options, and prognosis, as well as information that helps the clinician know the patient-as-person-his or her values, beliefs, and fears. ${ }^{84}$ Here, an ask-tell-ask approach is helpful-clinicians can monitor patients' information needs by asking the patient what might be useful to know, frame the information in different ways, and confirm the patient's understanding. ${ }^{85}$ The clinician should also check with the patient to avoid a common trap-incorrectly assuming that the patient's perspective is similar to his or her own. Physicians' misconceptions about patients' beliefs are common even if a physician and patient have known each other for years. ${ }^{86}$ Emotions are a form of information; these should be acknowledged and explored because they commonly affect how patients, families, and clinicians make decisions.

\section{Shared Deliberation}

Deliberation involves exploring the degree to which preferences are articulated or tacit, clear or nebulous, stable or unstable, informed or uninformed, and influenced by family, friends, and clinicians. As we noted previously, Mr Grayson's preferences first seemed stable, then became unstable as he became better informed. Shared deliberation includes explicit elementsexploring pros and cons of each option-as well as implicit elements, such as feelings (eg, trust) and personality (eg, tendency to avoid decisions, propensity to attend to details). Patients often express themselves indirectly (eg, a story about a relative $)^{16,87}$; clinicians should be attentive to and explore these clues to discern patients' needs for information and support.

Shared deliberation avoids premature simplification and promotes multiple perspectives (eg, "This treatment may help you live slightly longer, but may cause nerve damage that would affect your ability to work with your hands."). It promotes reflection (eg, What am I/you assuming that might not be true?) and transparency (eg, explaining their own reasoning and ask patients to do the same). Shared deliberation assesses the degree to which patients feel understood. It involves acknowledging uncertainty ${ }^{8,88}$ and explores the degree to which uncertainty provokes anxiety or comfort (by allowing room for hope). ${ }^{4}$ Sometimes clinicians may need to introduce uncertainty (eg, new options), rather than reduce it, and help patients tolerate the increased anxiety that results. To the degree that decision support technology and decision aids promote deliberation in the context of healing relationships, ${ }^{14,89}$ they can also promote shared mind.

\section{Shared Decisions}

Early descriptions of patient-centered decision making tended to be transactional_ - patient and physician were presumed to have disparate views, and a negotiated approach was proposed in which differences might be resolved (Table 1). ${ }^{90-92}$ At one extreme, an arms treaty approach (eg, pain contracts) may be necessary in some circumstances. The other end of the spectrum - an interactional approach-is based on consensus, trust, and relationship (an attunement-based approach). Interactional care emphasizes curiosity and consensus, not just negotiation and consent, and awareness and empathy rather than concreteness and distance. Although explicit agreement about a decision or plan of care is necessary to ascertain informed consent, explicit agreements should not be conflated with the attunement

\begin{tabular}{|lll}
\hline Table 1. Transactional Care and Interactional Care \\
\hline Component & Transactional Care & Interactional Care \\
\hline Information & Information exchange & Shared knowledge \\
& Knowing about the patient & Knowing the patient-as-person \\
& Understanding the illness & Understanding illness-in-context \\
& Information based on typical & Information tailored to individual need \\
& needs & Focus on relevance, comprehension, and \\
& Focus on information provision & meaning \\
& More nformation is better & Quantity of information depends on \\
& Removing affective compo- & patient needs \\
& nents of information & Acknowledging and adjusting for affective \\
& components of information \\
Degotiation & Shared deliberation \\
& Elicitation of preferences & Mutual discovery of preferences \\
& Negotiation and compromise & Collaborative cognition \\
& Contractual relationship & Collaborative "medical friendship" \\
& Removing affective influences & Affective engagement \\
& Focus on quantification of risk & Use of gut feelings and risk quantification \\
& Individual choice & Shared mind \\
& Focus on individual autonomy & Focus on relational autonomy \\
& Obtaining consent & Articulating and confirming consensus \\
& Delivering care & Engaging in care \\
Decision &
\end{tabular}


and collaborative cognition that characterize shared mind. When there is shared mind, physicians can better utilize motivational approaches to promote behavior change, overcome clinical inertia, and promote patient self-management. It will be important to understand how shared mind can be cultivated in short encounters, as well as during longitudinal clinical relationships.

In conclusion, not all decisions require shared mind, as, for example, in situations when individual preferences are clear, consistent, and coherent, or when urgent action must be taken. Decisions in the context of serious and chronic illness, such as Mr Grayson's, however, typically emerge from deliberations among individuals ${ }^{12} ;$ it is rare for an individual to come to clarity without the help of others.

\section{INTERACTIONAL CARE AND RELATIONAL AUTONOMY}

An interactional approach amends prior models of clinical care in its focus on relationships. Shared mind promotes relational autonomy, ${ }^{5,10,93}$ a view which recognizes that humans are social beings and that trusting relationships and personal knowledge, in fact, enhance autonomy by helping patients to process complex decisions that otherwise overwhelm the cognitive capacity of a single individual.

All communication between physicians and patients, including attempts to achieve shared mind, has dangers, the greatest of which is self-deception. Because clinicians' influences on decision making are ever present, self-awareness is key in helping clinicians provide appropriately tailored and balanced information, explore patients' values, and be attentive to their concerns. ${ }^{75,94,95}$ Lack of clinician self-awareness, by contrast, can lead to blindness to power differences between clinicians and patients (and within families); clinicians can unknowingly cross the line from collaboration to substituted decision making or coercion. Similarly, unwanted paternalism can masquerade as shared mind when the unexamined values of the physician overwhelm unspoken values of the patient and if the patient does not feel empowered to speak for him or herself. Misunderstandings or mistrust can lead clinicians to believe that verbal assent indicates the presence of shared mind. Thus, shared mind depends on enhancing clinicians' capacity for mindfulness and self-monitoring, ${ }^{96,97}$ as well as helping patients to be fully engaged in care. ${ }^{98}$

Shared mind, like caring, may be difficult to measure, but that difficulty should not diminish its importance. Direct observation of clinical encounters and patient and clinician surveys reveal some markers of shared mind, such as, for example, the degree to which clinicians and patients have beliefs, emotions, and val- ues in common, and, when they do not, the degree to which they can articulate each others' perspectives. ${ }^{86}$ Checking for mutual understanding and consensus are behaviors that can be observed, measured, and monitored. Ultimately, for the practicing clinician shared mind may prove to be a useful concept, as are presence and compassion, for identifying qualities of interactions worth cultivating and identifying when its absence interferes with clinical care.

By drawing attention to shared mind, clinicians can observe when it is present and when it is not, be attentive to the mutability of patients' preferences, and note ways in which they and others can make helpful contributions to decision-making processes and enhancing patient autonomy. Medical decision making should consider not only the individual perspectives of patients, their families, and members of the health care team but also the perspectives that emerge from the interactions among them.

To read or post commentaries in response to this article, see it online at http://www.annfammed.org/cgi/content/full/9/5/454.

Key words: Decision making; professional-patient relations; cooperative behavior; communication; patient participation; humans; patient preference; choice behavior

Submitted January 28, 2011; submitted, revised, June 8, 2011; accepted June 23, 2011.

Funding support: The ground-work for this article was supported in part by the American Board of Internal Medicine Foundation and the Commonwealth Fund.

Acknowledgements: This article is informed by discussions about shared decision making, patient-centered care, collaborative cognition, shared mind, and relational autonomy with valued colleagues, including Paul Duberstein, PhD, Glyn Elwyn, MD, Kevin Fiscella, MD, MPH, Paul Haidet, MD, Cara Lesser, and Kurt Stange, MD, PhD. In addition we thank Vikki Entwistle, PhD, Richard Kravitz, MD, MPH, and Ellen Peters, $\mathrm{PhD}$, for their review of an earlier version of the article.

\section{References}

1. Elwyn G, Miron-Shatz T. Deliberation before determination: the definition and evaluation of good decision making. Health Expect. 2010;13(2):139-147.

2. Kon AA. The shared decision-making continuum. JAMA. 2010;304 (8):903-904.

3. Quill TE, Brody H. Physician recommendations and patient autonomy: finding a balance between physician power and patient choice. Ann Intern Med. 1996;125(9):763-769.

4. Epstein RM, Alper BS, Quill TE. Communicating evidence for participatory decision making. JAMA. 2004;291(19):2359-2366.

5. Entwistle VA, Carter SM, Cribb A, McCaffery K. Supporting patient autonomy: the importance of clinician-patient relationships. J Gen Intern Med. 2010;25(7):741-745.

6. Entwistle VA, Watt IS. Patient involvement in treatment decisionmaking: the case for a broader conceptual framework. Patient Educ Couns. 2006;63(3):268-278. 
7. Rapley T. Distributed decision making: the anatomy of decisions-inaction. Soc Health Illness. 2008;30(3):429-444.

8. Charles C, Gafni A, Whelan T. Decision-making in the physicianpatient encounter: revisiting the shared treatment decision-making model. Soc Sci Med. 1999;49(5):651-661.

9. Charles C, Gafni A, Whelan T. Shared decision-making in the medical encounter: what does it mean? (or it takes at least two to tango) Soc Sci Med. 1997;44(5):681-692.

10. Mendick N, Young B, Holcombe C, Salmon P. The ethics of responsibility and ownership in decision-making about treatment for breast cancer: triangulation of consultation with patient and surgeon perspectives. Soc Sci Med. 2010;70(12):1904-1911.

11. Wirtz V, Cribb A, Barber N. Patient-doctor decision-making about treatment within the consultation-a critical analysis of models. Soc Sci Med. 2006;62(1):116-124.

12. Lown BA, Clark WD, Hanson JL. Mutual influence in shared decision making: a collaborative study of patients and physicians. Health Expect. 2009;12(2):160-174

13. Elwyn G, Stiel M, Durand MA, Boivin J. The design of patient decision support interventions: addressing the theory-practice gap. J Eval Clin Pract. 2010; Aug 3 [epub ahead of print].

14. Elwyn G, Edwards A, Frosch D, Volandes A. Investing in deliberation: a definition and classification of decision support interventions for people facing difficult health decisions. Med Decis Making 2010;30(6):01-711.

15. Peters E, Lipkus I, Diefenbach MA. The functions of affect in health communications and in the construction of health preferences. J Commun. 2006;56(Suppl 1):S140-S162.

16. Levinson W, Gorawara-Bhat R, Lamb J. A study of patient clues and physician responses in primary care and surgical settings. JAMA. 2000;284(8):1021-1027.

17. Saba GW, Wong ST, Schillinger D, et al. Shared decision making and the experience of partnership in primary care. Ann Fam Med. 2006;4(1):54-62.

18. Zlatev J, Racine TP, Sinha C, Itkonen E. The Shared Mind: Perspec tives on Intersubjectivity. Amsterdam/Philadelphia, PA: John Benjamins Publishing Co; 2008.

19. Rusbult CE, Van Lange PAM. Why we need interdependence theory. Soc Personality Psychol Compass. 2008;2(5):2049-2070.

20. Seaburn DB, McDaniel SH, Kim S, Bassen D. The role of the family in resolving bioethical dilemmas: clinical insights from a family systems perspective. J Clin Ethics. 2005;15(2):123-134.

21. Haidet P, Paterniti DA. "Building" a history rather than "taking" one: a perspective on information sharing during the medical interview. Arch Intern Med. 2003;163(10):1134-1140.

22. Shields CG, Epstein RM, Fiscella K, et al. Influence of accompanied encounters on patient-centeredness with older patients. J Am Board Fam Pract. 2005;18(5):344-354.

23. Epstein RM, Peters E. Beyond information: exploring patients' preferences. JAMA. 2009;302(2):195-197.

24. Lichtenstein S, Slovic P. The Construction of Preference. New York, NY: Cambridge University Press; 2006.

25. Slovic P. The construction of preference. Am Psychol. 1995;50(5): 364-371.

26. Nisbett RE, Wilson TD. Telling more than we can know: Verbal reports on mental processes. Psychol Rev. 1977;84:231-259.

27. Ubel PA, Loewenstein G, Schwarz N, Smith D. Misimagining the unimaginable: the disability paradox and health care decision making. Health Psychol. 2005;24(4, Suppl):S57-S62.

28. Wilson TD. Strangers to Ourselves: Discovering the Adaptive Unconscious. Cambridge, MA: Belknap Press of Harvard University Press; 2002.

29. Cassell EJ, Leon AC, Kaufman SG. Preliminary evidence of impaired thinking in sick patients. Ann Intern Med. 2001;134(12):1120-1123.
30. Dibartolo PM, Brown TA, Barlow DH. Effects of anxiety on attentional allocation and task performance: an information processing analysis. Behav Res Ther. 1997;35(12):1101-1111.

31. Oei NY, Everaerd WT, Elzinga BM, van Well S, Bermond B. Psychosocial stress impairs working memory at high loads: an association with cortisol levels and memory retrieval. Stress. 2006;9(3):133-141.

32. Robinson SJ, Sünram-Lea SI, Leach J, Owen-Lynch PJ. The effects of exposure to an acute naturalistic stressor on working memory, state anxiety and salivary cortisol concentrations. Stress. 2008;11(2):115-124.

33. Balsa Al, McGuire TG. Prejudice, clinical uncertainty and stereotyping as sources of health disparities. J Health Econ. 2003;22(1):89-116.

34. van Ryn M. Research on the provider contribution to race/ethnicity disparities in medical care. Med Care. 2002;40(1)(Suppl):I140-I151.

35. West CP, Tan AD, Habermann TM, Sloan JA, Shanafelt TD. Association of resident fatigue and distress with perceived medical errors. JAMA. 2009;302(12):1294-1300.

36. Croskerry P. The importance of cognitive errors in diagnosis and strategies to minimize them. Acad Med. 2003;78(8):775-780.

37. Burgess DJ. Are providers more likely to contribute to healthcare disparities under high levels of cognitive load? How features of the healthcare setting may lead to biases in medical decision making. Med Decis Making. 2010;30(2):246-257.

38. Muroff JR, Jackson JS, Mowbray CT, Himle JA. The influence of gender, patient volume and time on clinical diagnostic decision making in psychiatric emergency services. Gen Hosp Psychiatry. 2007;29(6):481-488.

39. Peters E, Dieckmann NF, Västfjäll D, Mertz CK, Slovic P, Hibbard JH. Bringing meaning to numbers: the impact of evaluative categories on decisions. J Exp Psychol Appl. 2009;15(3):213-227.

40. Croskerry P, Norman G. Overconfidence in clinical decision making. Am J Med. 2008;121(5)(Suppl):S24-S29.

41. Dijker A, Koomen W. Stereotyping and attitudinal effects under time pressure. Eur J Soc Psychol. 1998;26:61-74.

42. Suchman AL, Matthews DA. What makes the patient-doctor relationship therapeutic? Exploring the connexional dimension of medical care. Ann Intern Med. 1988;108(1):125-130.

43. Batson CD. These things called empathy: eight related but distinct phenomena. In: Decety J, Ickes W, eds. The Social Neuroscience of Empathy. Cambridge, MA: Bradford; 2009:3-15.

44. Decety J, Lamm C. Empathy versus personal distress: recent evidence from social neuroscience. In: Decety J, Ickes W, eds. The Social Neuroscience of Empathy. Cambridge, MA: Bradford; 2009:199-213.

45. Decety J. Empathy, sympathy and the perception of pain. Pain. 2009;145(3):365-366.

46. Eisenberg N, Eggum ND. Empathic responding: sympathy and personal distress. In: Decety J, Ickes W, eds. The Social Neuroscience of Empathy. Cambridge, MA: Bradford; 2009:71-83.

47. Pfeifer JH, Dapretto M. Mirror, mirror, in my mind: empathy, interpersonal competence, and the mirror neuron system. In: Decety J, Ickes W, eds. The Social Neuroscience of Empathy. Cambridge, MA: Bradford; 2009:183-197.

48. Gallese V, Keysers C, Rizzolatti G. A unifying view of the basis of social cognition. Trends Cogn Sci. 2004;8(9):396-403.

49. Meegan SP, Berg CA. Contexts, functions, forms, and processes of collaborative everyday problem solving in older adulthood. Int J Behav Dev. 2002;26:6-15.

50. Riess H. Empathy in medicine-a neurobiological perspective. JAMA. 2010;304(14):1604-1605.

51. Siegel DJ. The Developing Mind: Toward a Neurobiology of Interpersonal Experience. New York, NY: Guilford Press; 1999.

52. Singer T, Lamm C. The social neuroscience of empathy. Ann N Y Acad Sci. 2009;1156:81-96. 
53. Balint M. The Doctor, His Patient, and the Illness. New York, NY: International Universities Press; 1957.

54. Branch WT, Malik TK. Using 'windows of opportunities' in brief interviews to understand patients' concerns. JAMA. 1993;269(13): 1667-1668.

55. Watzlawick PJ, Weakland JH, Fisch R. Change: Principles of Problem Formation and Problem Resolution. New York, NY: W.W. Norton \& Co; 1974.

56. Norton SA, Bowers BJ. Working toward consensus: providers' strategies to shift patients from curative to palliative treatment choices. Res Nurs Health. 2001;24(4):258-269.

57. Branch WT Jr, Frankel R, Gracey CF, et al. A good clinician and a caring person: longitudinal faculty development and the enhancement of the human dimensions of care. Acad Med. 2009;84(1):117-125.

58. Palmer P. The Courage to Teach: Exploring the Inner Landscape of a Teacher's Life. 10th ed. New York, NY: Jossey-Bass; 2007.

59. Weick KE, Roberts $\mathrm{KH}$. Collective mind in organizations-heedful interrelating on flight decks. Adm Sci Q. 1993;38(3):357-381.

60. Haidet $P$, Fecile ML, West HF, Teal CR. Reconsidering the team concept: educational implications for patient-centered cancer care. Patient Educ Couns. 2009;77(3):450-455.

61. Wenger E. Communities of Practice: Learning, Meaning, and Identity. Cambridge, MA: Cambridge University; 1998.

62. Morganti F, Carassa A, Riva G. Enacting Intersubjectivity: A Cognitive and Social Perspective on the Study of Interactions. New York, NY: IOS Press; 2008.

63. Varela FJ, Thompson E, Rosch E. The Embodied Mind: Cognitive Science and Human Experience. Cambridge, MA: MIT Press; 1991.

64. Hayward JW, Varela FJ. Gentle Bridges: Conversations with the Dalai Lama on the Sciences of Mind. Boston, MA: Shambhala Publications, Inc; 1992.

65. Thompson E. Empathy and enculturation. In: Mind in Llife: Biology, Phenomenology, and the Sciences of Mind. Boston, MA: Harvard University Press; 2007:382-411.

66. Vygotsky L. Mind in Society. The Development of Higher Psychological Processes. Cambridge, MA: Harvard University Press; 1978.

67. Wittgenstein L. Remarks on the Philosophy of Psychology. Oxford: Blackwell; 1980.

68. Stern D. The Present Moment in Psychotherapy and Everyday Life. 1st ed. New York, NY: Norton \& Co; 2004.

69. Siegel DJ. The Mindful Brain: Reflection and Attunement in the Cultivation of Well-Being. New York, NY: W.W. Norton; 2007.

70. Rizzolatti G, Craighero L. The mirror-neuron system. Annu Rev Neurosci. 2004;27:169-192.

71. Ickes W. Empathic accuracy: its links to clinical, cognitive, developmental, social, and physiological psychology. In: Ickes W, Decety J, eds. The Social Neuroscience of Empathy. Cambridge, MA: Bradford; 2009:57-70

72. Rizzolatti G, Sinigaglia C, Anderson F. Mirrors in the Brain: How Our Minds Share Actions, Emotions, and Experience. Oxford University Press; 2008.

73. Kreps GL. Applying Weick's model of organizing to health care and health promotion: highlighting the central role of health communication. Patient Educ Couns. 2009;74(3):347-355.

74. Weick KE. Sensemaking in Organizations. 2nd ed. Thousand Oaks, CA: Sage Publications; 1995.

75. Epstein RM. Mindful practice. JAMA. 1999;282(9):833-839.

76. Fioratou E, Flin R, Glavin R, Patey R. Beyond monitoring: distributed situation awareness in anaesthesia. Br J Anaesth. 2010;105(1):83-90.

77. Stacey R. Complexity and Creativity in Organizations. 1st ed. San Francisco, CA: Barrettt-Koehler Publishers; 1996.
78. Pearce W, Cronan V. Communication, Action, and Meaning: the Creation of Social Realities. New York, NY: Praeger; 1980.

79. Street RL Jr. Aiding medical decision making: a communication perspective. Med Decis Making. 2007;27(5):550-553.

80. Street RL Jr, Makoul G, Arora NK, Epstein RM. How does communication heal? Pathways linking clinician-patient communication to health outcomes. Patient Educ Couns. 2009;74(3):295-301.

81. Street RL Jr, Gordon HS, Ward MM, Krupat E, Kravitz RL. Patient participation in medical consultations: why some patients are more involved than others. Med Care. 2005;43(10):960-969.

82. Epstein RM, Street RL Jr. Patient-Centered Communication in Cancer Care: Promoting Healing and Reducing Suffering. Bethesda, MD: National Cancer Institute, NIH; 2007.

83. Epstein RM, Korones DN, Quill TE. Withholding information from patients-when less is more. N Engl J Med. 2010;362(5):380-381.

84. Epstein RM, Street RL. A framework for patient-centered communication in cancer care. In: Patient-Centered Communication in Cancer Care. Bethesda, MD: National Cancer Institute, NIH; 2007;17-38.

85. Back AL, Arnold RM, Baile WF, Tulsky JA, Fryer-Edwards K. Approaching difficult communication tasks in oncology. CA Cancer J Clin. 2005;55(3):164-177.

86. Street RL, Jr., Haidet P. How well do doctors know their patients? Factors affecting physician understanding of patients' health beliefs. J Gen Intern Med. 2010;26(1):21-27.

87. Lang F, Floyd MR, Beine KL. Clues to patients' explanations and concerns about their illnesses. A call for active listening. Arch Fam Med. 2000;9(3):222-227.

88. Politi MC, Han PK, Col NF. Communicating the uncertainty of harms and benefits of medical interventions. Med Decis Making. 2007;27(5):681-695.

89. Street RL Jr. Mediated consumer-provider communication in cancer care: the empowering potential of new technologies. Patient Educ Couns. 2003;50(1):99-104.

90. Lazare A, Eisenthal S, Frank A. Clinician/patient relations II: conflict and negotiation. In: Lazare A, ed. Outpatient Psychiatry: Diagnosis and Treatment. Baltimore, MD: Williams \& Wilkins; 1989;137-152.

91. Lazare $A$. The interview as clinical negotiation. In: Lipkin MJr, Putnam SM, Lazare A, eds. The Medical Interview. New York, NY Springer-Verlag; 1995;50-64.

92. Quill TE. Recognizing and adjusting to barriers in doctor-patient communication. Ann Intern Med. 1989;111(1):51-57.

93. Surbone A. Telling the truth to patients with cancer: what is the truth? Lancet Oncol. 2006;7(11):944-950.

94. Smith RC, Dorsey AM, Lyles JS, Frankel RM. Teaching self-awareness enhances learning about patient-centered interviewing. Acad Med. 1999;74(11):1242-1248.

95. Novack DH, Suchman AL, Clark W, Epstein RM, Najberg E, Kaplan C. Working Group on Promoting Physician Personal Awareness, American Academy on Physician and Patient. Calibrating the physician. Personal awareness and effective patient care. JAMA. 1997; 278(6):502-509.

96. Krasner MS, Epstein RM, Beckman H, et al. Association of an educational program in mindful communication with burnout, empathy, and attitudes among primary care physicians. JAMA. 2009; 302(12):1284-1293.

97. Epstein RM, Siegel DJ, Silberman J. Self-monitoring in clinical practice: a challenge for medical educators. J Contin Educ Health Prof. 2008;28(1):5-13.

98. Kinnersley P, Edwards A, Hood K, et al. Interventions before consultations for helping patients address their information needs. Cochrane Database Syst Rev. 2007;(3):CD004565. 